\title{
Influence of Stratospheric Intrusion on the Surface Ozone Levels in India
}

\author{
Nandita D. Ganguly \\ Department of Physics, St. Xavier's College, Ahmedabad 380009, India \\ Correspondence should be addressed to Nandita D. Ganguly, ganguly.nandita@gmail.com
}

Received 5 April 2012; Accepted 21 June 2012

Academic Editors: S. Iizuka, N. A. Mazzeo, and D. Moreira

Copyright () 2012 Nandita D. Ganguly. This is an open access article distributed under the Creative Commons Attribution License, which permits unrestricted use, distribution, and reproduction in any medium, provided the original work is properly cited.

The surface ozone levels in some Indian cities have increased significantly in the recent years. Ozone being toxic to the living system and an important contributor to anthropogenic global warming, enhanced surface ozone may have adverse effects on the air quality and climate. Transport of ozone from the stratosphere to the troposphere causes stratospheric ozone to decrease and tropospheric ozone to increase, which can in turn have serious consequences for life on earth. Since stratosphere-troposphere exchange (STE) is an important factor influencing the ozone concentration in the troposphere, this paper investigates probably for the first time the possible contribution of STE events to the observed enhanced surface ozone levels for cities covering from north to south of India. It is concluded that apart from transport processes and in situ photochemical production, STE also influences the observed high-surface ozone levels in Indian cities to a small extent (8\%-16\%). STE events producing high-surface ozone levels are found to be higher at high latitudes.

\section{Introduction}

The amount of surface ozone at any location depends upon the amount of its supply from the stratosphere, rate of photochemical production, transport from other regions, and the rate of its destruction on the earth's surface either due to dry deposition or photochemical loss mechanisms [1-3]. Downward transport of stratospheric ozone [4, 5], called stratosphere-troposphere exchange (STE) of ozone is an important and significant natural source of surface ozone. The mechanisms leading to STE are tropopause folds, cutoff lows, and quasiadiabatic transports along isentropic surfaces $[5,6]$. Ozone being toxic to the living system, intense exposure to surface ozone may result in persistent decrease in lung function, pneumonia, influenza, asthma, and decrease in crop yield. Transport of ozone from the stratosphere to the troposphere may cause surface ozone levels to increase resulting in adverse consequences for life on earth. The ambient air quality standards for surface ozone in India are $180 \mu \mathrm{g} / \mathrm{m}^{3}$ (92 ppbv) for 1-hour average and $100 \mu \mathrm{g} / \mathrm{m}^{3}$ (51 ppbv) for 8-hour average [7].

It has been observed in the recent years that the background surface ozone levels have increased significantly in some Indian cities $[8,9]$. Several studies suggest that rapid and deep STE events may be associated with severe weather [10-12] and cause ozone peaks at the surface $[13,14]$. When compared with high-surface ozone episodes induced photo chemically near the Earth's surface, relatively little study has been reported for high-surface ozone cases induced by STE in India. Although these episodes are relatively uncommon, they have been reported to produce transient peak ozone concentrations of around $100 \mathrm{ppbv}$ at sea level and concentrations in excess of $250 \mathrm{ppbv}$ in mountain regions [15] in other parts of the world. In view of the above observations, this paper is aimed to identify the Indian cities where the surface ozone is likely to be affected by STE by examining all the case studies in detail over a period of 11 years from 1998-2008.

\section{Measurement Site and Data}

The Indian subcontinent lies between $8^{\circ} \mathrm{N}-36^{\circ} \mathrm{N}$ latitude. The five surface ozone monitoring stations, namely, New Delhi $\left(28.4^{\circ} \mathrm{N}, 77.13^{\circ} \mathrm{E} ; 214.42\right.$ meters above sea level), Nagpur $\left(21^{\circ} \mathrm{N}, 79^{\circ} \mathrm{E} ; 310\right.$ meters above sea level), Pune 


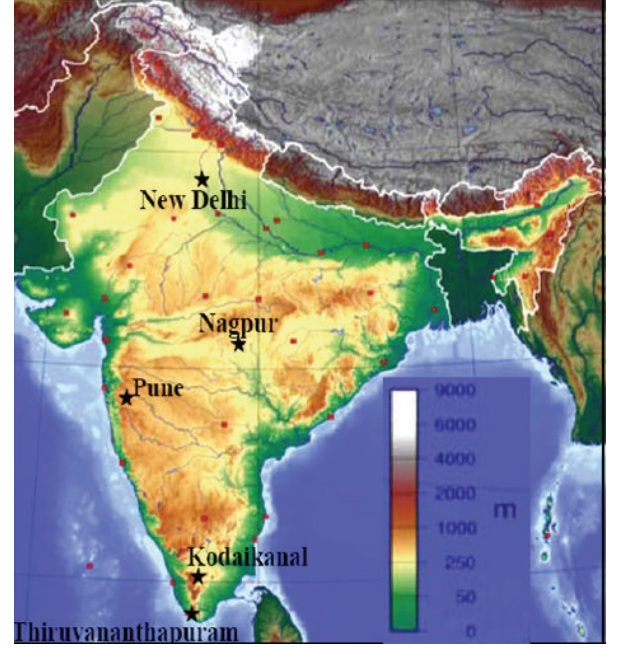

Figure 1: Topographic map of India depicting the measurement sites (source: http://www.mapsindia.com/).

$\left(18.5^{\circ} \mathrm{N}, 73.5^{\circ} \mathrm{E} ; 560\right.$ meters above sea level), Kodaikanal $\left(10^{\circ} \mathrm{N}, 77.5^{\circ} \mathrm{E} ; 2,133\right.$ meters above sea level), and Thiruvananthapuram $\left(8.28^{\circ} \mathrm{N}, 76.56^{\circ} \mathrm{E} ; 60\right.$ meters above sea level) extending from North to South India (Figure 1), have entirely different geographical morphology and hence different local climatic conditions. The topographic map of India depicting the measurement sites was obtained from the website: http://www.mapsindia.com/. The daily maximum surface ozone at New Delhi, Pune, Kodaikanal, and Thiruvananthapuram over the period from 1998-2008 and at Nagpur during the period from 2005-2007 measured by electrochemical method have been obtained from India Meteorological Department (IMD). 5-day back-trajectory at different pressure levels and potential vorticity at the tropopause $(100 \mathrm{hPa})$ has been retrieved from the European Centre for Medium-Range Weather Forecasts (ECMWF). The vertical pressure velocity, relative humidity, and geopotential height maps have been retrieved from NCEP/NCAR reanalysis [16]. Daily global $2.0^{\circ} \times 4.0^{\circ}$ gridded data of surface carbon monoxide $(\mathrm{CO})$ and methane $\left(\mathrm{CH}_{4}\right)$ were obtained from TES (Tropospheric Emission Spectrometer) on NASA's EOS (Earth Observing System) spacecraft. Total Nitrogen dioxide $\left(\mathrm{NO}_{2}\right)$ column data from Ozone monitoring instrument (OMI) was obtained from the website http://www.temis.nl/. Fire count data representing biomass burning from the ATSR World Fire Atlas has been taken from Ionia products of European Space Agency.

\section{Analysis and Results}

The day characterized by maximum surface ozone concentration in each month was identified and the linear trend of this monthly maximum surface ozone data was plotted for the entire period of available data set. The surface ozone levels at Pune and Thiruvananthapuram indicated a small decreasing trend, while that at New Delhi, Nagpur, and Kodaikanal indicated a small increasing trend (Figure 2)

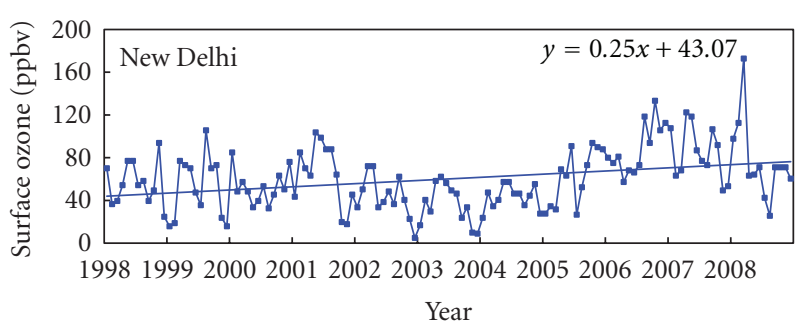

(a)

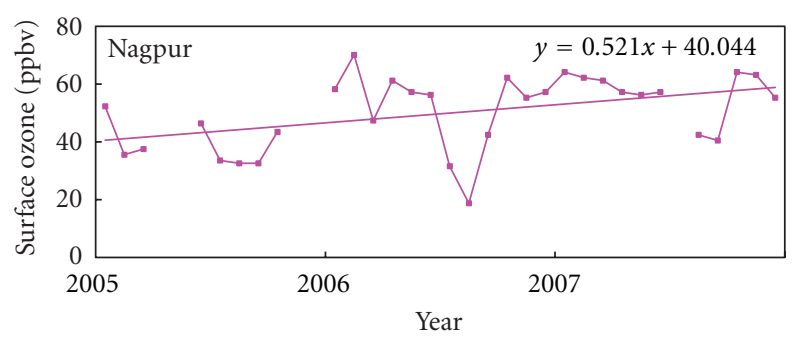

(b)

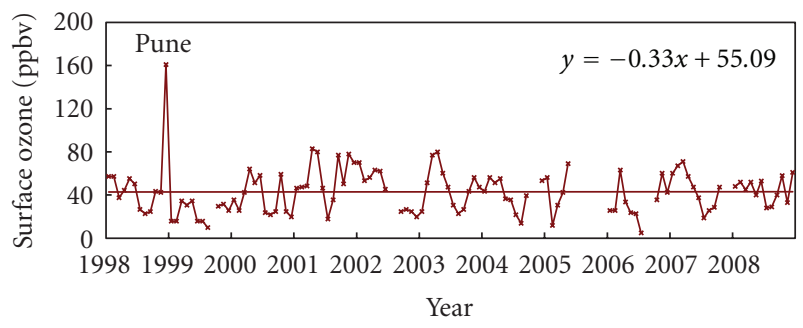

(c)

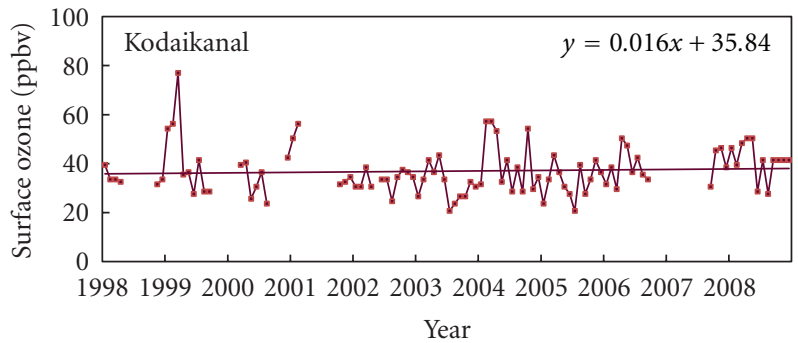

(d)

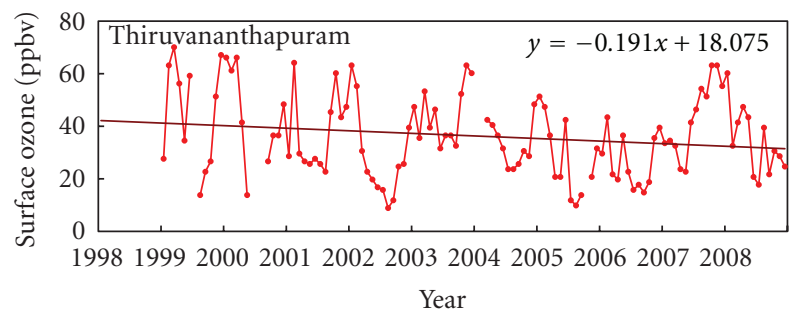

(e)

FIgURE 2: Time series of surface ozone at different Indian cities.

over the period of study. Several studies in the recent years indicate that surface ozone, even at concentrations less than the ambient air quality standards, can flare harmful effects in human beings $[17,18]$. Therefore instead of considering ozone episodes greater than the ambient air quality standard as critical, higher than normal ozone episodes were identified 
TABle 1: Upper control limit (UCL) for surface ozone at different Indian cities, estimated statistically (Gupta and Kapoor, 1993 [19]) from the mean control chart using the monthly maximum surface ozone data at New Delhi, Pune, Kodaikanal, and Thiruvananthapuram over the period from 1998-2008 and at Nagpur during the period from 2005-2007.

\begin{tabular}{lc}
\hline City & UCL for surface ozone \\
\hline New Delhi $\left(28.4^{\circ} \mathrm{N}, 77.13^{\circ} \mathrm{E}\right)$ & $79.5 \mathrm{ppbv}$ \\
Nagpur $\left(21^{\circ} \mathrm{N}, 79^{\circ} \mathrm{E}\right)$ & $57.6 \mathrm{ppbv}$ \\
Pune $\left(18.5^{\circ} \mathrm{N}, 73.5^{\circ} \mathrm{E}\right)$ & $57.3 \mathrm{ppbv}$ \\
Kodaikanal $\left(10^{\circ} \mathrm{N}, 77.5^{\circ} \mathrm{E}\right)$ & $43.4 \mathrm{ppbv}$ \\
Thiruvananthapuram $\left(8.28^{\circ} \mathrm{N}, 76.56^{\circ} \mathrm{E}\right)$ & $47.3 \mathrm{ppbv}$ \\
\hline
\end{tabular}

by employing the statistic mean control chart (MCC), and the causes leading to these episodes were investigated in detail.

MCC is a time plot of observations with a statistically calculated control limit. If the variations in surface ozone follow a normal cyclic pattern throughout the year (due to seasonal changes), then all the points in the time plot should lie within the control limit. When an observation exceeds the upper control limit (UCL), some new and unanticipated source of variation (either natural or anthropogenic) is likely to be operating, and a search for the special cause should be initiated. The UCL for surface ozone at different Indian stations has been estimated statistically [19] from the MCC by using the monthly maximum surface ozone data for the entire period of available data set. The results are summarized in Table 1:

$$
\begin{gathered}
\overline{\bar{X}}=\sum \frac{\overline{\mathbf{X}_{K}}}{11} ; \quad \bar{R}=\sum \frac{\mathbf{R}_{K}}{11}, \\
\text { (for New Delhi, Pune, Kodaikanal, } \\
\text { and Thiruvananthapuram), } \\
\overline{\bar{X}}=\sum \frac{\overline{\mathbf{X}_{K}}}{3} ; \quad \bar{R}=\sum \frac{\mathbf{R}_{K}}{3}, \quad \text { (for Nagpur), }
\end{gathered}
$$

where $\overline{\mathbf{X}_{K}}$ is the yearly mean surface ozone for $n=12$ months of the $k$ th year. Range $\mathbf{R}_{k}=$ (Maximum ozoneMinimum ozone) observed for the $k$ th year. $k=1,2,3, \ldots$, 11 (years from 1998-2008 for New Delhi, Pune, Kodaikanal, and Thiruvananthapuram) and $k=1,2,3$ (years from 20052007 for Nagpur)

$$
\mathrm{UCL}=\overline{\bar{X}}+A_{2} \bar{R}
$$

The value of constant $A_{2}$ corresponding to $n=12$ is 0.266 and is obtained from standard statistical control table [19]. The days characterized by surface ozone concentration higher than UCL was identified from the monthly maximum surface ozone dataset for each station (Figure 3), and the possible association of this unusually high surface ozone concentration with STE was investigated. Potential vorticity $(\mathrm{PV})$ is a measure of the spin of air. Stratospheric air is characterized by high PV and low relative humidity

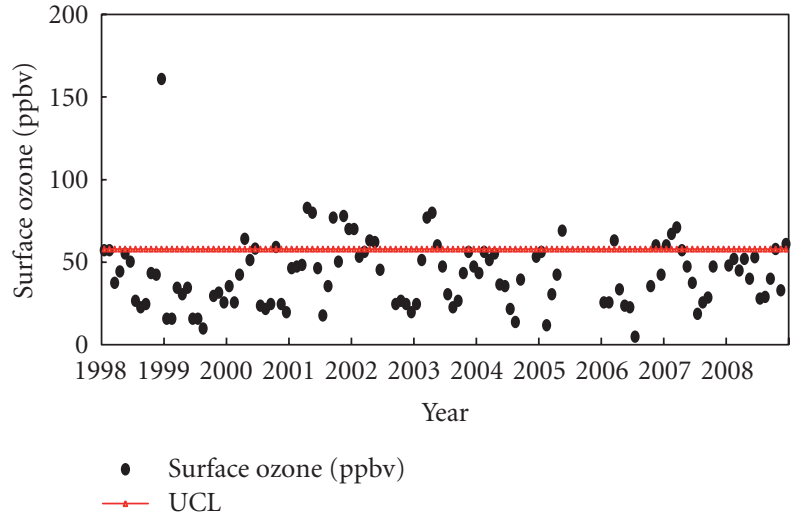

Figure 3: Upper control limit (UCL) for surface ozone at Pune, estimated statistically (Gupta and Kapoor, 1993 [19]) from the mean control chart using the monthly maximum surface ozone data from 1998-2008.

(RH). According to the WMO definition of dynamical tropopause [20], PV values exceeding $1.6 \mathrm{pvu}$ ( $1 \mathrm{pvu}=$ $10^{-6} \mathrm{~m}^{2} \mathrm{Kkg}^{-1} \mathrm{~s}^{-1}$ ) at the tropopause indicate the presence of air masses having stratospheric origin. Therefore, the presence of air masses characterized by $\mathrm{PV}>1.6$ and $\mathrm{RH}<$ $60 \%$ has been considered as a signature of stratospheric air similar to that in the study by Cristofanelli et al. [21]. To identify and exclude air masses possibly influenced by polluted air or biomass burning plumes, the $\mathrm{CO}, \mathrm{CH}_{4}$, and $\mathrm{NO}_{2}$ concentration and fire counts were taken into account. The 5 -day back-trajectories at 1000,925 , and $850 \mathrm{hPa}$ pressure levels were examined to determine the place from where the air parcels had originated. This information was in turn used to check the possibility of horizontal transport of ozone and its precursors from these areas. The vertical pressure velocity $\left(\mathrm{Pa} \mathrm{s}^{-1}\right)$ was examined to confirm the downward transport of ozone from the stratosphere. As pressure decreases with altitude, positive values of vertical pressure velocity indicate sinking motion and negative values indicate rising motion in the atmosphere. The days characterized by higher than normal concentration of $\mathrm{CO}, \mathrm{CH}_{4}, \mathrm{NO}_{2}$, and fire counts, vertical pressure velocity indicating upward transport of ozone and back trajectories from high ozone or ozone precursor areas were excluded from this study. Further, the geopotential maps in the upper troposphere were examined to detect the formation of cutoff lows. The total ozone concentration was examined for \pm 10 days from the day of STE event to investigate if the increase in surface ozone was due to tropopause folding.

One such case study at Pune on 24 November, 2006 is presented as an illustration (Figure 4). The geopotential height map at $850 \mathrm{hPa}$ pressure level indicates the formation of a trough, which is typically preceded by stormy weather and colder air at the surface. The vertical pressure velocity at the tropopause indicated downward transport of ozone from the stratosphere. The PV value was $>1.6$ and $\mathrm{RH}$ at the tropopause were low (20\%), indicating the presence of air masses having stratospheric origin. The fire counts representing biomass burning were absent at all places lying 


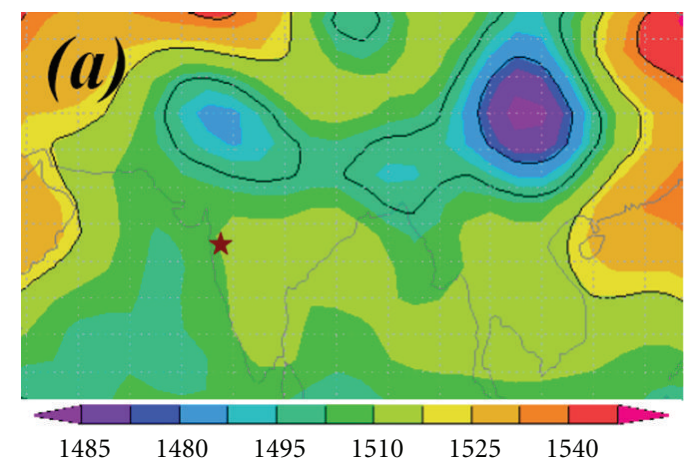

(a)

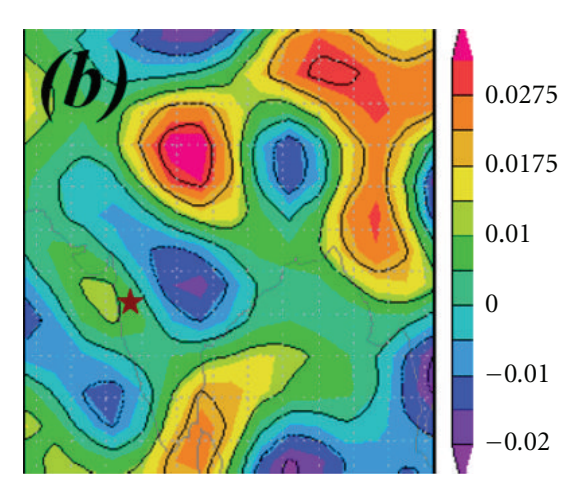

(b)

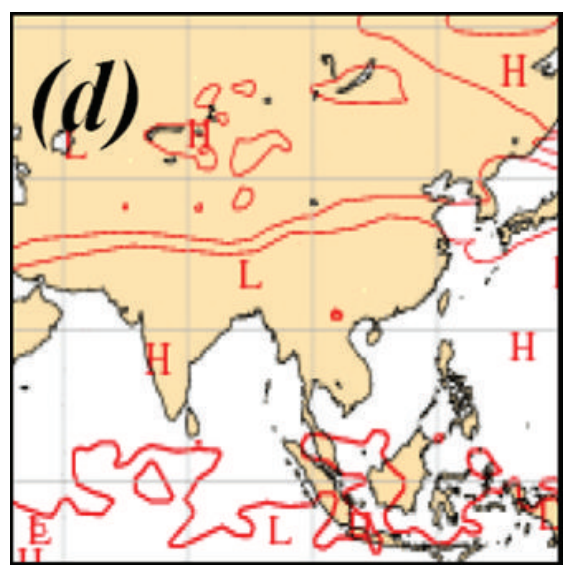

(d)

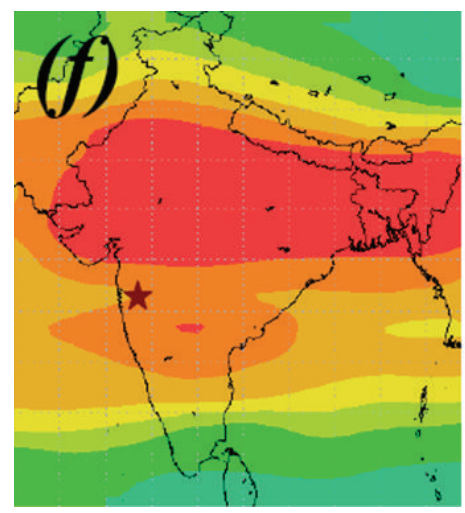

(f)

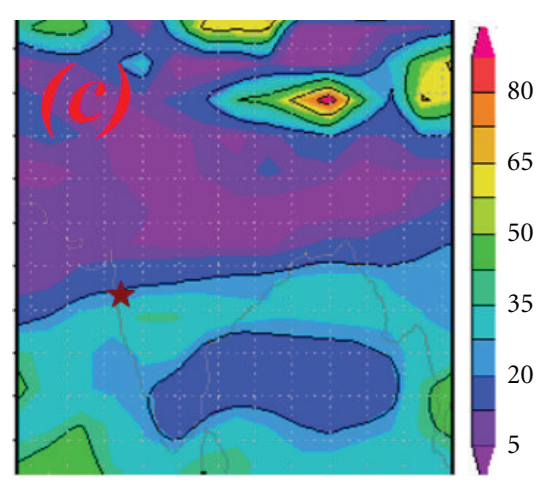

(c)

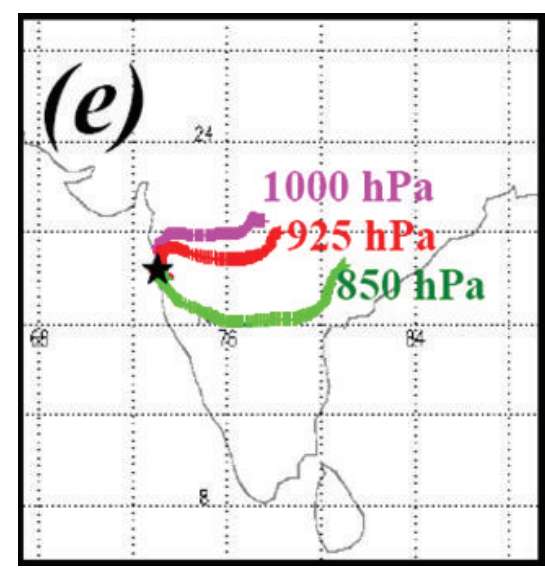

(e)

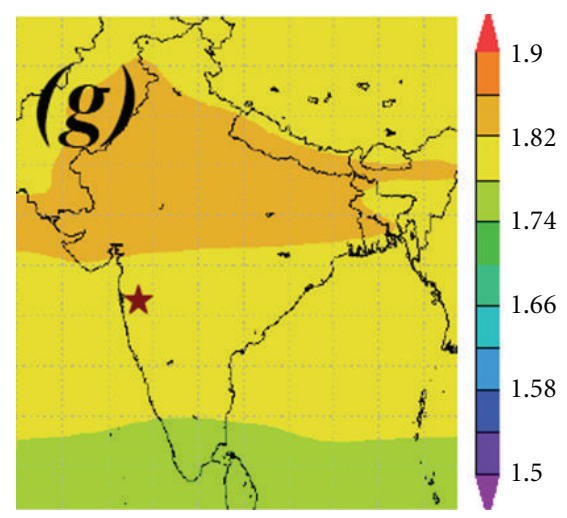

(g)

Figure 4: Continued. 


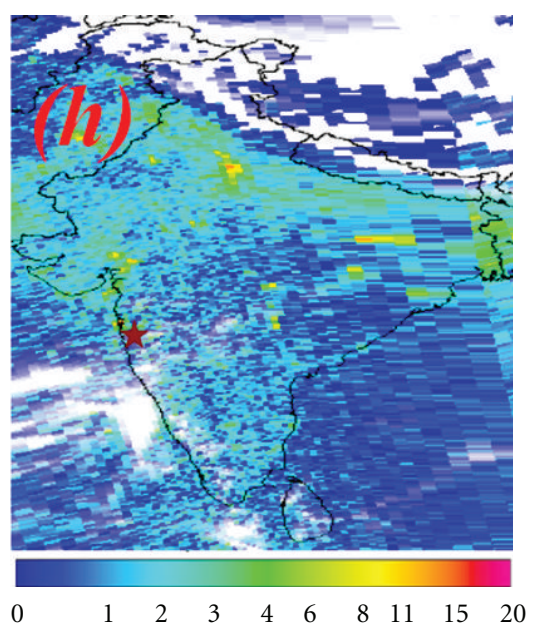

(h)

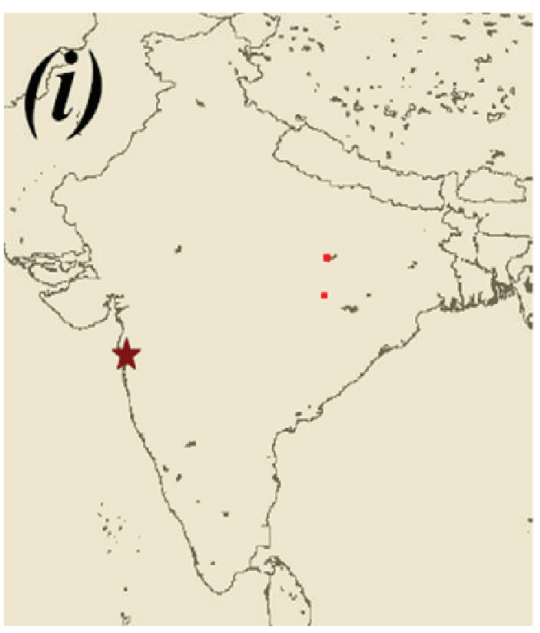

(i)

Figure 4: (a) Geopotential height (meter) map at $850 \mathrm{hPa}$, (b) vertical pressure velocity $\left(\mathrm{Pa} \cdot \mathrm{s}^{-1}\right.$ ) at the tropopause, (c) relative humidity $(\%)$ at $300 \mathrm{hPa}$ pressure level, (d) potential vorticity at the tropopause, (e) 5-day back trajectories at $1000 \mathrm{hPa}$ (pink), $925 \mathrm{hPa}(\mathrm{red})$, and $850 \mathrm{hPa}$ (green) pressure levels, (f) tropospheric CO $\left(10^{-1} \mathrm{ppmv}\right),(\mathrm{g}) \mathrm{CH}_{4}(\mathrm{ppmv}),(\mathrm{h}) \mathrm{NO}_{2}\left(10^{15} \mathrm{molecules} \cdot \mathrm{cm}^{2}\right)$, and (i) fire counts at Pune on 24 November 2006 (sources of data: NCEP Reanalysis, ECMWF, TES, OMI, and ASTR world fire atlas).

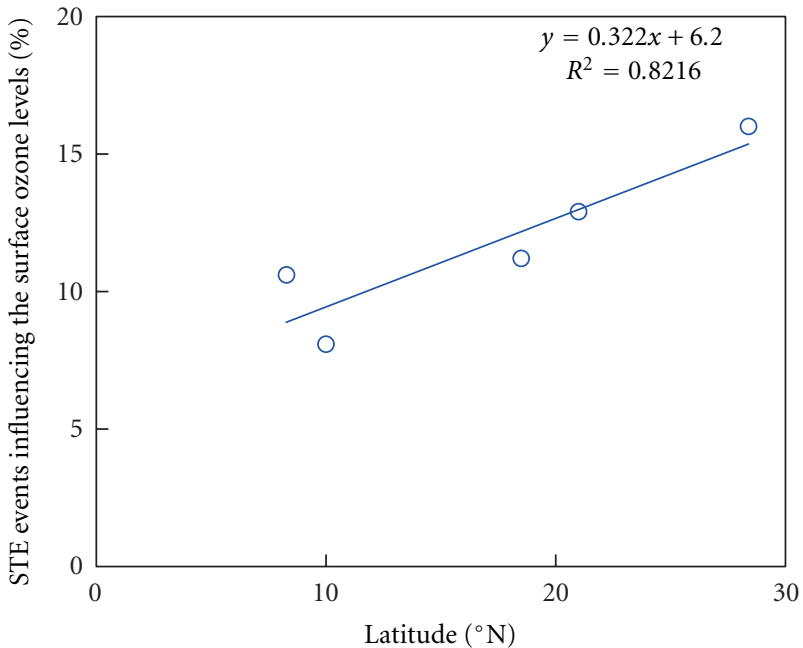

(a)

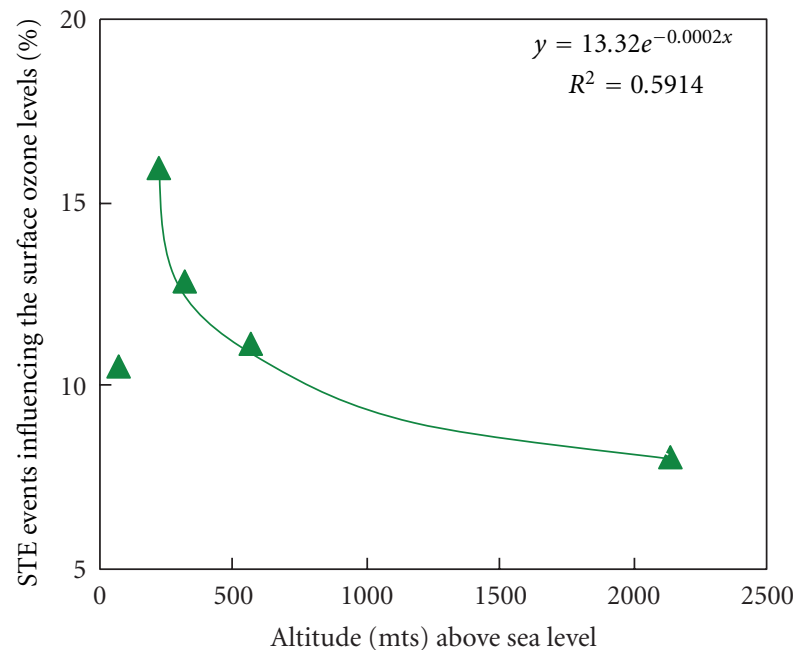

(b)

FIGURE 5: Figure representing the percentage dependence of STE events producing high surface ozone levels on the order of latitude and altitude.

in and around the station under consideration and along the path of back trajectories. Similar results were observed on all high ozone days at all stations considered in the study. These characteristic features suggest that the enhanced surface ozone observed on these occasions may be a consequence of stratospheric intrusion.

Multiple regression analysis (Figure 5) was used to determine the amount of dependence of STE events producing high-surface ozone levels on the order of latitude. A regression equation indicates the nature of the relationship between the variables and, in particular, the extent to which the variables are associated with one another. The regression equation and the respective correlation coefficients are noted in the plot. The coefficient of determination " $R$ " was found to be 0.8216 , indicating that STE events producing highsurface ozone levels depend by an amount of $82.16 \%$ on the order of the Latitude. This is because deep STE events of ozone occur more frequently at high latitudes [22] compared to low Indian latitudes. Between October and May, the intertropical convergence zone (ITCZ) is located to the south of Thiruvananthapuram [23]. The vertical velocity profiles exhibit a strong ascending motion over the mean position of the ITCZ, and a strong subsidence between $10^{\circ} \mathrm{N}-30^{\circ} \mathrm{N}$ latitudes [24, 25], thus affecting the STE processes over India. It appears from Figure 5 that STE events influencing the high surface ozone levels in India decrease exponentially with 
increase in altitude. However, this may be because all the measurement stations having high altitude, which have been considered in this study, lie at low latitudes where deep STE of ozone is not very prominent.

\section{Conclusions}

This paper investigates the possible contribution of STE events to the observed higher than normal surface ozone levels for few Indian cities. It is concluded that apart from transport processes and in situ photochemical production, STE also influences the observed high-surface ozone levels in Indian cities to a small extent $(8 \%-16 \%)$. STE events producing high-surface ozone levels are found to be higher at high latitudes.

\section{Acknowledgments}

The surface ozone data for Indian cities were obtained from the India Meteorological Department. Topographic map of India depicting the measurement sites was obtained from the website: http://www.mapsindia.com/. Tropospheric carbon monoxide and methane data were obtained from Tropospheric Emission Spectrometer on NASA's EOS (Earth Observing System) spacecraft. The 5-day back trajectories and potential vorticity were retrieved from the European Centre for Medium-Range Weather Forecasts. Total nitrogen dioxide column data from Ozone monitoring instrument (OMI) was obtained from the website http://www.temis.nl/. The vertical pressure velocity, relative humidity, and geopotential maps were retrieved from NCEP Reanalysis (Kalnay et al., 1996 [16]). The ATSR World Fire Atlas data has been taken from Ionia products of European Space Agency. The author also acknowledges her gratitude to ISRO for providing grant under the CAWSES India project for the above study and Professor J. N. Goswami, Director of Physical Research Laboratory, Ahmedabad, India, for providing library facility.

\section{References}

[1] C. E. Junge, "Global ozone budget and exchange between stratosphere and troposphere," Tellus, vol. 14, no. 4, pp. 363-377, 1962.

[2] P. J. Crutzen, "Photochemical reactions initiated by and influencing ozone in unpolluted tropospheric air," Tellus, vol. 26, no. $1-2$, pp. 47-57, 1974.

[3] H. Van Dop, R. Guicherit, and R. W. Lanting, "Some measurements of the vertical distribution of ozone in the atmospheric boundary layer," Atmospheric Environment, vol. 11, no. 1, pp. 65-71, 1977.

[4] W. K. Hocking, T. Carey-Smith, D. W. Tarasick et al., "Detection of stratospheric ozone intrusions by windprofiler radars," Nature, vol. 450, no. 7167, pp. 281-284, 2007.

[5] J. R. Holton, P. H. Haynes, M. E. McIntyre, A. R. Douglass, R. B. Rood, and L. Pfister, "Stratosphere-troposphere exchange," Reviews of Geophysics, vol. 33, no. 4, pp. 403-439, 1995.

[6] G. Vaughan, "Stratosphere-troposphere exchange of ozone," in Tropospheric Ozone, I. S. A. Isaksen, Ed., pp. 125-135, D Reidel, Dordrecht, The Netherlands, 1988.
[7] Gazette of India, "part 3, section 4, 18," 2009, New Delhi/ Kartika 27, 123.

[8] T. K. Mandal, G. Beig, and A. P. Mitra, "Ozone and UV scenario over India," Scientific Report 22, Center on Global Change, NPL, New Delhi, India, 2004.

[9] S. L. Jain, B. C. Arya, A. Kumar, S. D. Ghude, and P. S. Kulkarni, "Observational study of surface ozone at New Delhi, India," International Journal of Remote Sensing, vol. 26, no. 16, pp. 3515-3524, 2005.

[10] K. A. Browning and R. Reynolds, "Diagnostic study of a narrow cold-frontal rainband and severe winds associated with a stratospheric intrusion," Quarterly Journal, vol. 120, no. 516, pp. 235-257, 1994.

[11] K. A. Browning and B. W. Golding, "Mesoscale aspects of a dry intrusion within a vigorous cyclone," Quarterly Journal, vol. 121, no. 523, pp. 463-493, 1995.

[12] M. A. Goering, W. A. Gallus, M. A. Olsen, and J. L. Stanford, "Role of stratospheric air in a severe weather event: analysis of potential vorticity and total ozone," Journal of Geophysical Research D, vol. 106, no. 11, pp. 11813-11823, 2001.

[13] A. Stohl, N. Spichtinger-Rakowsky, P. Bonasoni et al., "The influence of stratospheric intrusions on alpine ozone concentrations," Atmospheric Environment, vol. 34, no. 9, pp. 1323$1354,2000$.

[14] A. Stohl, H. Wernli, P. James et al., "A new perspective of stratosphere-troposphere exchange," Bulletin of the American Meteorological Society, vol. 84, no. 11, pp. 1565-1473, 2003.

[15] T. D. Davies and E. Schuepbach, "Episodes of high ozone concentrations at the earth's surface resulting from transport down from the upper troposphere/lower stratosphere: a review and case studies," Atmospheric Environment A, vol. 28, no. 1, pp. 53-68, 1994.

[16] E. Kalnay, M. Kanamitsu, R. Kistler et al., "The NCEP/NCAR 40-year reanalysis project," Bulletin of the American Meteorological Society, vol. 77, no. 3, pp. 437-471, 1996.

[17] E. L. Avol, W. C. Navidi, E. B. Rappaport, and J. M. Peters, "Acute effects of ambient ozone on asthmatic, wheezy, and healthy children," Research Report, no. 82, pp. 1-30, 1998.

[18] R. J. Delfino, A. M. Murphy-Moulton, and M. R. Becklake, "Emergency room visits for respiratory illnesses among the elderly in Montreal: association with low level ozone exposure," Environmental Research, vol. 76, no. 2, pp. 67-77, 1998.

[19] S. C. Gupta and V. K. Kapoor, Fundamentals of Applied Statistics, chapter 1, Sultan Chand and sons, New Delhi, India, 1993.

[20] World Meteorological Organization, "Atmospheric ozone 1985: global ozone research and monitoring report," WMO Report 16, Geneva, Switzerland, 1986.

[21] P. Cristofanelli, A. Bracci, M. Sprenger et al., "Tropospheric ozone variations at the nepal climate Observatory-Pyramid (Himalayas, $5079 \mathrm{~m}$ a.s.l.) and influence of deep stratospheric intrusion events," Atmospheric Chemistry and Physics, vol. 10, no. 14, pp. 6537-6549, 2010.

[22] N. D. Ganguly and C. Tzanis, "Study of Stratospheretroposphere exchange events of ozone in India and Greece using ozonesonde ascents," Meteorological Applications, vol. 18, no. 4, pp. 467-474, 2011.

[23] G. J. Roelofs and J. Lelieveld, "Model analysis of stratospheretroposphere exchange of ozone and its role in the tropospheric ozone budget," in Chemistry and Radiation Changes in the Ozone Layer, C. Zerefos et al., Ed., pp. 25-43, Kluwer Academic Publishers, Dodrecht, The Netherlands, 2000.

[24] J. P. Peixoto and A. H. Oort, Physics of Climate, American Institute of Physics, New York, NY, USA, 1992. 
[25] V. H. Annes, K. Mohankumar, and P. V. Joseph, "Winter and summer hadley circulations over Peninsular India as monitored by mst radar at Gadanki $\left(13.47^{\circ} \mathrm{N}, 79.18^{\circ} \mathrm{E}\right)$," International Journal of Climatology, vol. 21, no. 5, pp. 593-601, 2001. 

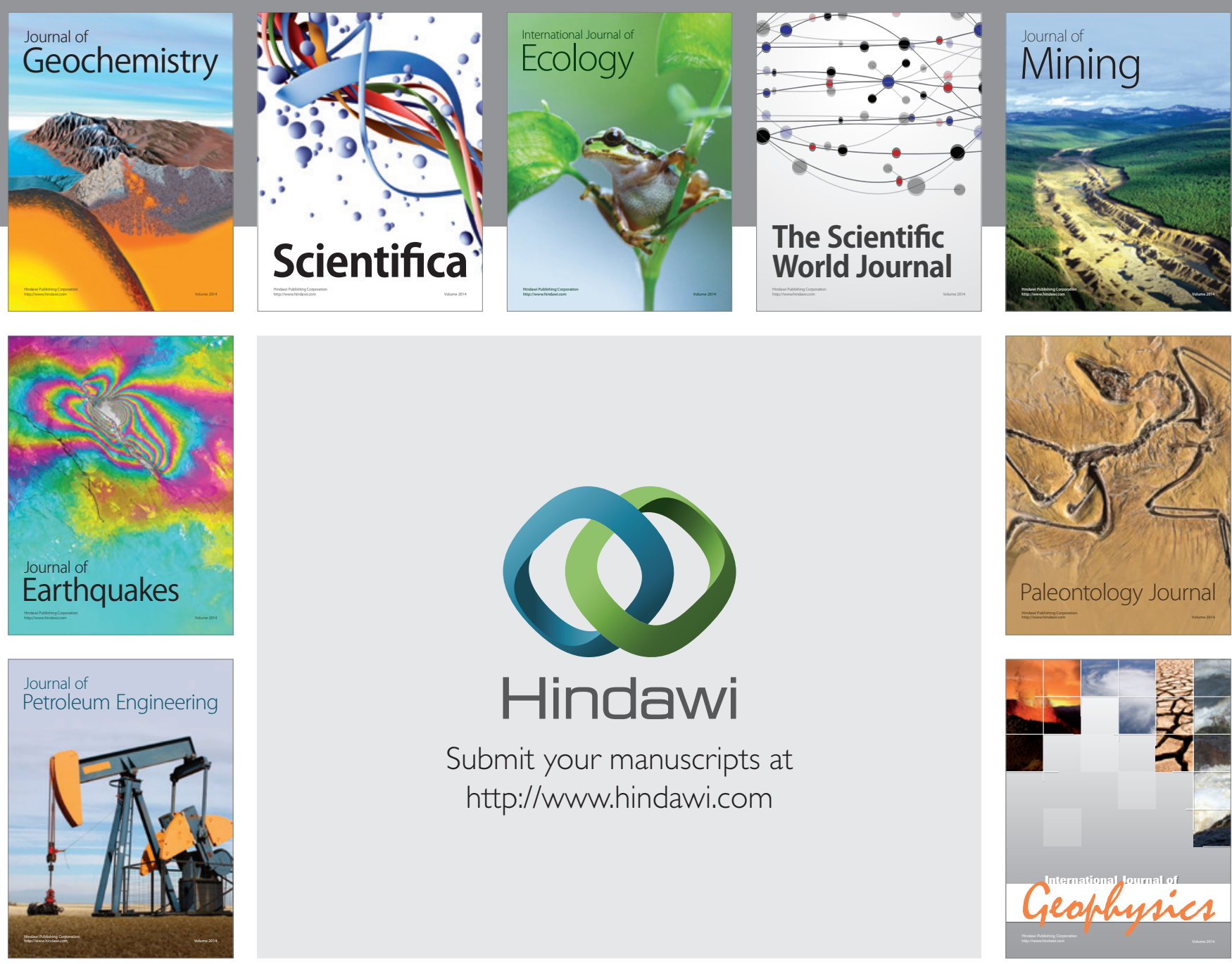

Submit your manuscripts at

http://www.hindawi.com
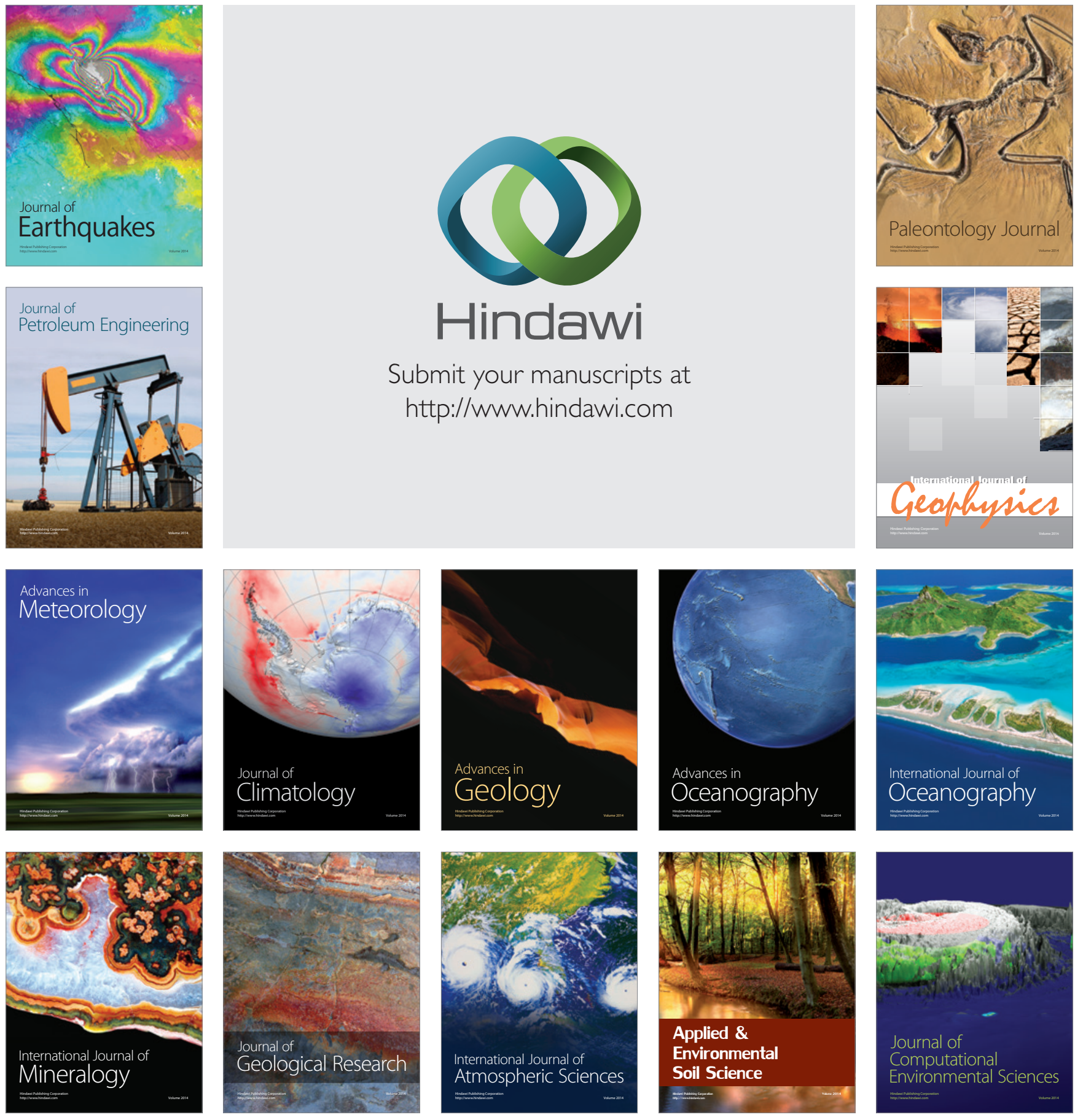